\title{
Routine treatment and outcome of breast cancer in younger versus elderly patients: results from the SENORA project of the prospective German TMK cohort study
}

\author{
Thomas Fietz ${ }^{1} \cdot$ Mark-Oliver Zahn $^{2} \cdot$ Andreas Köhler $^{3} \cdot$ Erik Engel $^{4} \cdot$ \\ Melanie Frank ${ }^{5} \cdot$ Lisa Kruggel $^{6} \cdot$ Martina Jänicke $^{6} \cdot$ Norbert Marschner $^{7}$ (D) \\ the TMK-Group (Tumour Registry Breast Cancer)
}

Received: 25 July 2017 / Accepted: 6 October 2017 / Published online: 13 October 2017

(c) The Author(s) 2017. This article is an open access publication

\begin{abstract}
Purpose There is an ongoing discussion about 'undertreatment' of breast cancer in elderly patients. Due to low accrual into clinical trials, level 1 evidence is scarce. We report prospective data of elderly patients with breast cancer treated by medical oncologists in Germany.

Methods The SENORA project within the prospective cohort study TMK (Tumour Registry Breast Cancer) was conducted in 82 centres from 2007-2015. Among 2316 patients, half were enrolled with curative and half with palliative treatment intention. Overall, 478 patients (21\%) were aged $\geq 70$.

Results In the adjuvant setting, elderly patients aged $\geq 70$ had more advanced tumour stages at diagnosis and a higher prevalence of comorbidities than younger patients. Elderly patients received adjuvant chemotherapy less frequently, yet the 3 -year disease-free survival was similar (86\% vs. $88 \%$ ). In the palliative setting, elderly patients more frequently
\end{abstract}

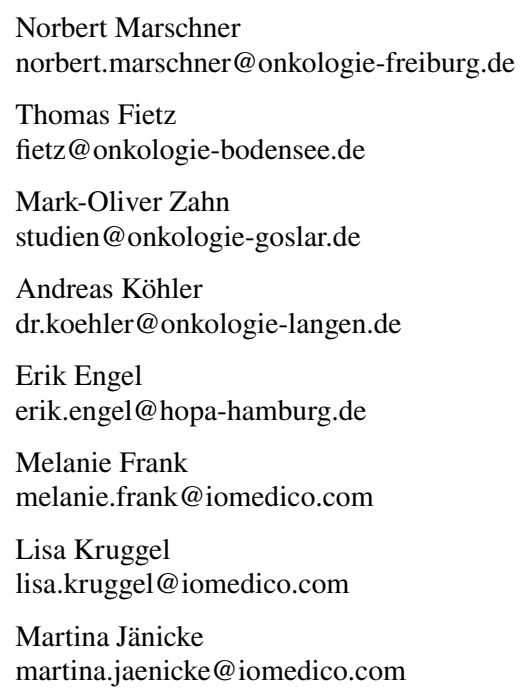

received endocrine therapy and less frequently chemotherapy. Their median overall survival [24.9 months, 95\% CI (confidence interval) 20.0-30.2] was significantly shorter than that of younger patients (39.7 months, 95\% CI 34.944.2). A Cox proportional hazards model showed a significantly increased risk of mortality for: age $\geq 70$ at start of therapy, negative HR- or HER2-status, higher number of metastatic sites, more comorbidities and high tumour grading at diagnosis.

Conclusions Our results shed light on the routine treatment of elderly patients with breast cancer. A regression model demonstrated that age is but one of various prognostic factors determining the shorter overall survival of elderly patients.

Keywords Breast neoplasms $\cdot$ Aged $\cdot$ Registries $\cdot$ Cohort studies · Outcome assessment $\cdot$ Prognosis

1 Outpatient-Centre for Internal Medicine, Haematology and Oncology, Virchowstr. 10c, 78224 Singen, Germany

2 Ambulatory Healthcare Centre (MVZ) Oncological Cooperation Harz, Kösliner Str. 14, 38642 Goslar, Germany

3 Outpatient-Centre for Haematology and Oncology, Röntgenstr. 6-8, 63225 Langen, Germany

4 Haematological-Oncological Practice Altona (HOPA), Hamburg, Germany

5 Statistics, iOMEDICO, Hanferstr. 28, 79108 Freiburg, Germany

6 Clinical Epidemiology and Health Economics, iOMEDICO, Hanferstr. 28, 79108 Freiburg, Germany

7 Outpatient-Centre for Interdisciplinary Oncology and Haematology, Wirthstrasse 11c, 79110 Freiburg, Germany 


\section{Introduction}

In Germany, breast cancer is the most frequently diagnosed cancer ( $31 \%$ of all cases), with women aged 70 or older at diagnosis representing $34 \%$ of these cases [1, 2]. In general, the risk of being diagnosed with breast cancer increases with age, affecting 1 in 48 women at age 45 and 1 in 28 women at age 65 [1]. The number of elderly individuals in our population is growing rapidly. While $17 \%$ of the German population was aged 60 and older in 1960, this proportion increased to $27 \%$ in 2013 [3]. Thus, the number of elderly patients with breast cancer continues to rise. Since elderly patients are more often affected by comorbidities or have an inferior general condition, the therapeutic options might need to be adjusted. As a woman aged 70 has a life expectancy of 16.8 years in Germany [4], treatment decision should not be guided by the chronological age, but needs to balance the risks and benefits, health status, life expectancy, individual preferences and sustained quality of life.

Prognostic factors influencing breast cancer outcome relate to tumour and patient characteristics [5-7]; the interactions between these factors are complex and not yet fully understood. In comparison to younger patients, breast tumours in older women tend to have less aggressive profiles and lower recurrence rates $[8,9]$, but the relative survival in women older than 70 has been reported to be lower [5, $10,11]$. Hampered by the underrepresentation of women aged $\geq 70$ in clinical trials, there are only limited data on treatment of this group of patients [12-15]. Several reports have stated deviations from the guidelines in treatment of breast cancer in elderly patients, especially concerning surgery and adjuvant chemotherapy [16-19]. This so-called undertreatment might be due to missing clinical evidence as the standard treatment is based on recommendations extrapolated from younger patients participating in clinical trials $[14,20]$. In addition, when assessing guideline conformity, factors preventing use of recommended treatments (such as comorbidities) are often missing. There is an urgent need for prospective clinical trials as well as population-based cohort studies tailored for elderly patients in order to optimise their treatment.

In this article, we present data on 2316 patients with breast cancer from the SENORA project within the TMK (Tumour Registry Breast Cancer). This prospective clinical cohort study recruits patients treated by office- and clinicbased medical oncologists, thus showing data from routine practice. We show patient and tumour characteristics as well as treatment details for the adjuvant and the palliative setting, both for younger patients and for patients aged $\geq 70$. Furthermore, we present the disease-free survival (DFS) as well as the overall survival (OS) for both younger and elderly patients and additionally present a multivariate regression model identifying factors influencing the OS.

\section{Patients and methods}

\section{Data source}

The TMK is an ongoing, open, longitudinal, multicentre, observational, prospective cohort study which started in 2007 . The study was approved by the responsible ethics committee and is registered at ClinicalTrials.gov (NCT01351584). Eligible patients are women aged $\geq 18$ years with histologically confirmed breast cancer, who received systemic antineoplastic treatment (endocrine therapy or chemotherapy). Written informed consent was obtained from all patients. Enrolment was restricted to patients who had signed informed consent no longer than 6 weeks after start of treatment, yet for the first 1000 patients with palliative treatment intention, the maximum span between start of first-line treatment and enrolment was 1 year. By project plan, patients were followed until death or for a maximum of 3 years. However, some sites provided update data on survival status after completion of the 3 year follow-up. The SENORA sub-project was set up in order to examine the treatment of elderly patients with breast cancer. 82 outpatient-centres and clinics for medical oncology located all over Germany actively recruited patients for the SENORA project between 2007 and 2011. The TMK has previously been described in detail [21].

\section{Cohort definition}

Between 2007 and 2011, 2613 patients had been recruited into the TMK. 74 patients were excluded because of incomplete basic medical data or not fulfilling inclusion criteria. 21 patients who received trastuzumab monotherapy were excluded as the sample size was too small for a separate group. Of the remaining 2518 patients, 202 received neoadjuvant therapy but only 13 of them were aged 70 or older, therefore, this patient subgroup will not be discussed further. The present analysis focuses on 2316 patients receiving adjuvant or palliative first-line chemo- or endocrine therapy (Fig. 1). 1838 of the patients were younger than 70, 478 patients were aged $\geq 70$. Outcome data including the OS are presented only for the prospectively enrolled patients, who had signed informed consent no longer than 6 weeks after the start of treatment to avoid overestimation of outcome (Fig. 1).

\section{Statistical analysis}

The aim of the SENORA project was the descriptive comparison of patient characteristics, treatment and outcome of elderly (age $\geq 70$ ) versus younger patients. Time to events was analysed using Kaplan-Meier estimates. For the prospectively enrolled patients in adjuvant treatment 


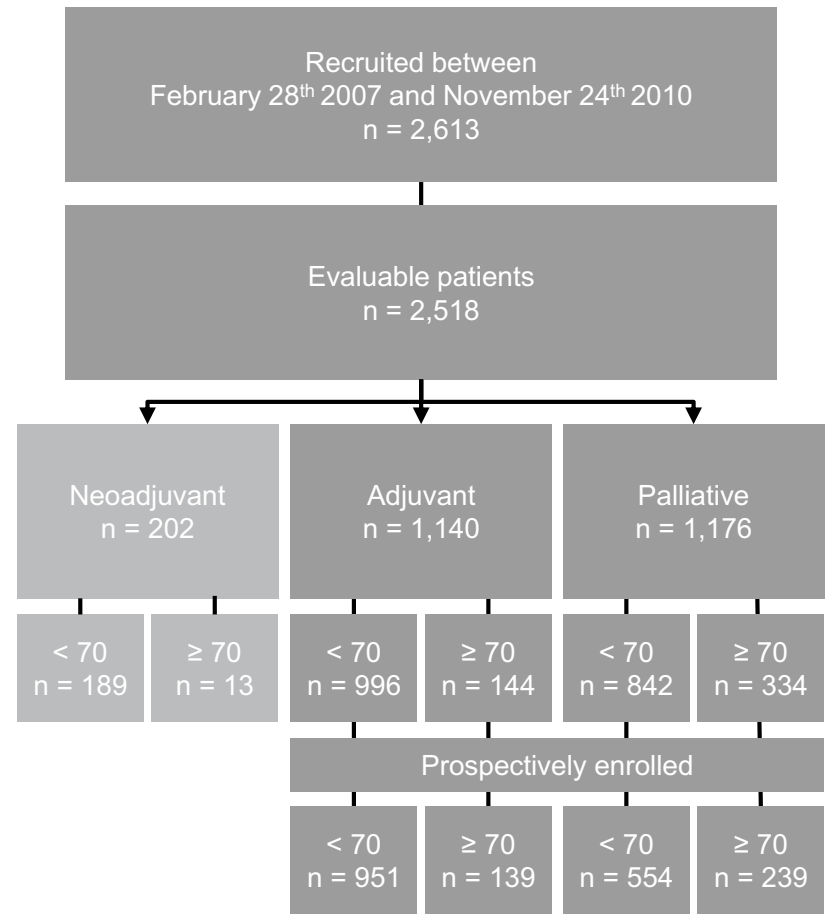

Fig. 1 Cohort definition. Number of patients enrolled in the TMK, split up according to the neoadjuvant, adjuvant or palliative treatment intention as well as to the age at start of therapy. Prospectively enrolled patients signed the informed consent no longer than 6 weeks after start of treatment

intention, DFS was defined as the interval between start of adjuvant treatment and the date of recurrence or death from any cause. Patients lost to follow-up or without recurrence were censored at last contact. For the prospectively enrolled patients with palliative treatment intention, PFS was defined as the interval between start of first-line therapy and the date of first progression or death. Patients without such an event before start of second-line therapy were censored at either the start of second-line therapy or at last contact, whatever came first. OS was defined as the interval between start of first-line therapy and the date of death from any cause. Patients alive or lost to follow-up were censored at last contact. DSS was calculated from start of first-line therapy until date of death due to breast cancer. Patients alive, lost to follow-up or with other causes of death were censored at last contact or at date of death. The treatment duration was calculated using a Kaplan-Meier estimate and defined as time from start of treatment until end of treatment or death. If no end of therapy was documented, patients were censored at last contact/end of documentation. The median follow-up period was calculated using the reverse Kaplan-Meier estimate [22]. All analyses were performed using IBM SPSS Statistics version 19.0 and SAS for Windows version 9.4. Exact binomial confidence intervals were calculated using $z$-test with StatSoft STATISTICA version 13.
For the prospectively enrolled patients with palliative treatment intention (maximum span of 6 weeks between start of treatment and signed informed consent), a Cox proportional hazards model was used to identify potential independent prognostic factors for survival. The following independent variables were examined for the model: age at start of first-line treatment, body mass index (BMI) at enrolment, Charlson comorbidity index, CCI [23] at diagnosis, HR-status and HER2-status at diagnosis, stage and tumour grading at diagnosis as well as resection of the primary tumour. Furthermore, these treatment details at start of first-line therapy were included: prior neoadjuvant or adjuvant chemotherapy; number of metastatic sites and location of metastases. Nonvisceral metastases were defined as skin, bone or lymph node metastases. Confidence intervals (CI) for the regression coefficients were based on the Wald statistics. All presented $P$ values are two-sided. 5\% will be interpreted as significant. There were no adjustments to the level of significance.

\section{Results}

\section{Patient and tumour characteristics in the adjuvant setting}

Basic demographic and clinical data of the patients receiving adjuvant therapy are presented in Table 1, comparing patients younger than 70 years to those aged $\geq 70$. Median age at start of adjuvant therapy was 55 years $(<70)$ compared to 73 years $(\geq 70)$. The prevalence of comorbidities was higher for elderly $(38 \% \mathrm{CCI} \geq 1)$ than for younger patients $(18 \% \mathrm{CCI} \geq 1)$, with hypertension documented most frequently (57\%). 35 (24\%) of the elderly patients were $\geq 75$ years old, 8 (6\%) of them $\geq 80$ years old. Regarding the receptor status, the two subgroups were comparable. Elderly patients more often presented with advanced tumour stage at diagnosis (26\% stage III vs. $14 \%$ of the younger patients) and more often had lymph node involvement (58\% vs. $48 \%)$.

\section{Patient and tumour characteristics in the palliative setting}

Table 2 presents the basic characteristics of the two patient subgroups receiving palliative therapy. Median age at diagnosis was 53 versus 72 years, the BMI was similar. $75 \%$ of the elderly patients presented with comorbidities compared to $49 \%$ of the younger patients. $169(51 \%)$ of the elderly patients were $\geq 75$ years old, $66(20 \%)$ of them $\geq 80$ years old. $49 \%$ of the patients aged $\geq 70$ had hypertension (vs. $29 \%$ of the younger patients) and $20 \%$ diabetes mellitus (vs. $7 \%$ ). Generally, the prevalence of comorbidities was higher 
Table 1 Patient and tumour characteristics in the adjuvant setting

\begin{tabular}{|c|c|c|c|c|}
\hline \multirow[t]{2}{*}{ Characteristic } & \multicolumn{2}{|c|}{$<70(n=996)$} & \multicolumn{2}{|c|}{$\geq 70(n=144)$} \\
\hline & Median & Min-Max & Median & Min-Max \\
\hline Age at start of therapy, years & 55.1 & $21.6-69.9$ & 72.8 & $70.0-85.5$ \\
\hline Characteristic & $n$ & $\%$ & $n$ & $\%$ \\
\hline \multicolumn{5}{|l|}{ BMI at enrolment ${ }^{\mathrm{a}}$} \\
\hline Underweight & 5 & 0.5 & 1 & 0.7 \\
\hline Normal & 454 & 45.6 & 41 & 28.5 \\
\hline Overweight & 294 & 29.5 & 53 & 36.8 \\
\hline Obese & 223 & 22.4 & 44 & 30.6 \\
\hline Unknown & 20 & 2.0 & 5 & 3.5 \\
\hline Patients with any comorbidity ${ }^{\mathrm{b}, \mathrm{c}, \mathrm{e}}$ & 470 & 47.2 & 118 & 81.9 \\
\hline Hypertension & 240 & 24.1 & 82 & 56.9 \\
\hline Diabetes mellitus & 69 & 6.9 & 2 & 14.6 \\
\hline Cardiovascular disease & 34 & 3.4 & 18 & 12.5 \\
\hline \multicolumn{5}{|l|}{ Charlson comorbidity index ${ }^{\mathrm{d}}$} \\
\hline $\mathrm{CCI}=0$ & 814 & 81.7 & 89 & 61.8 \\
\hline $\mathrm{CCI} \geq 1$ & 182 & 18.3 & 55 & 38.2 \\
\hline \multicolumn{5}{|l|}{ Receptor status at diagnosis } \\
\hline HR-positive, HER2-negative & 569 & 57.1 & 82 & 56.9 \\
\hline HR-positive, HER2-positive & 176 & 17.7 & 19 & 13.2 \\
\hline HR-negative, HER2-positive & 77 & 7.7 & 10 & 6.9 \\
\hline Triple negative & 147 & 14.8 & 26 & 18.1 \\
\hline Unknown & 27 & 2.7 & 7 & 4.9 \\
\hline \multicolumn{5}{|l|}{ Tumour stage at diagnosis } \\
\hline I & 268 & 26.9 & 26 & 18.1 \\
\hline II & 443 & 44.5 & 60 & 41.7 \\
\hline III & 141 & 14.2 & 38 & 26.4 \\
\hline Unknown $^{\mathrm{f}}$ & 144 & 14.5 & 20 & 13.9 \\
\hline \multicolumn{5}{|l|}{ Tumour grading at diagnosis } \\
\hline G1 & 74 & 7.4 & 11 & 7.6 \\
\hline G2 & 540 & 54.2 & 64 & 44.4 \\
\hline G3 & 371 & 37.2 & 65 & 45.1 \\
\hline GX & 11 & 1.1 & 4 & 2.8 \\
\hline \multicolumn{5}{|l|}{ Node stage at diagnosis } \\
\hline No & 502 & 50.4 & 58 & 40.3 \\
\hline N1 & 341 & 34.2 & 47 & 32.6 \\
\hline $\mathrm{N} 2$ & 84 & 8.4 & 22 & 15.3 \\
\hline N3 & 56 & 5.6 & 15 & 10.4 \\
\hline Unknown & 13 & 1.3 & 2 & 1.4 \\
\hline
\end{tabular}

$B M I$ body mass index $\left(\mathrm{kg} / \mathrm{m}^{2}\right), H R$ hormone receptor, HER2 human epidermal growth factor receptor 2, Max maximum, Min minimum

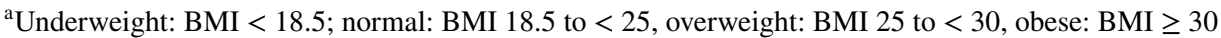

${ }^{\mathrm{b}}$ At start of therapy

${ }^{\mathrm{c}}$ At least one comorbidity according to Charlson [23] or additional concomitant diseases

${ }^{\mathrm{d}}$ Charlson Comorbidity Index (CCI) according to Quan et al. [24]

${ }^{\mathrm{e}}$ Multiple answers provided

${ }^{\mathrm{f}}$ For some patients the exact stage could not be determined because of unknown parameters (TX, NX, MX) 
Table 2 Patient and tumour characteristics in the palliative setting

\begin{tabular}{|c|c|c|c|c|}
\hline \multirow[t]{2}{*}{ Characteristic } & \multicolumn{2}{|c|}{$<70(n=842)$} & \multicolumn{2}{|c|}{$\geq 70(n=334)$} \\
\hline & Median & Min-Max & Median & Min-Max \\
\hline Age at diagnosis, years & 53.2 & $22.3-69.6$ & 71.6 & $37.1-90.2$ \\
\hline Age at start of therapy, years & 59.1 & $22.5-70.0$ & 75.1 & $70.0-92.8$ \\
\hline Characteristic & $n$ & $\%$ & $n$ & $\%$ \\
\hline \multicolumn{5}{|l|}{ BMI at enrolment ${ }^{\mathrm{a}}$} \\
\hline Underweight & 7 & 0.8 & 6 & 1.8 \\
\hline Normal & 344 & 40.9 & 123 & 36.8 \\
\hline Overweight & 262 & 31.1 & 115 & 34.4 \\
\hline Obese & 173 & 20.5 & 60 & 18.0 \\
\hline Unknown & 56 & 6.7 & 30 & 9.0 \\
\hline Patients with comorbidity ${ }^{\mathrm{d}, \mathrm{e}}$ & 415 & 49.3 & 250 & 74.9 \\
\hline Hypertension & 241 & 28.6 & 165 & 49.4 \\
\hline Diabetes mellitus & 55 & 6.5 & 65 & 19.5 \\
\hline Cardiovascular disease & 20 & 2.4 & 36 & 10.8 \\
\hline $\mathrm{CCI}=0^{\mathrm{f}}$ & 688 & 81.7 & 192 & 57.5 \\
\hline $\mathrm{CCI} \geq 1$ & 154 & 18.3 & 142 & 42.5 \\
\hline \multicolumn{5}{|l|}{ Receptor status at diagnosis } \\
\hline HR-positive, HER2-negative & 389 & 46.2 & 159 & 47.6 \\
\hline HR-positive, HER2-positive & 162 & 19.2 & 54 & 16.2 \\
\hline HR-negative, HER2-positive & 78 & 9.3 & 21 & 6.3 \\
\hline Triple negative & 93 & 11.0 & 28 & 8.4 \\
\hline Unknown & 120 & 14.3 & 72 & 21.6 \\
\hline \multicolumn{5}{|l|}{ Tumour grading at diagnosis } \\
\hline $\mathrm{G} 1 / 2$ & 428 & 50.8 & 183 & 54.8 \\
\hline $\mathrm{G} 3 / 4$ & 314 & 37.3 & 115 & 34.4 \\
\hline GX/Unknown & 100 & 11.9 & 36 & 10.8 \\
\hline \multicolumn{5}{|l|}{ Resection of primary tumour } \\
\hline R0 & 636 & 75.5 & 250 & 74.9 \\
\hline $\mathrm{R} 1 / 2$ & 63 & 7.5 & 35 & 10.5 \\
\hline RX/unknown & 143 & 17.0 & 49 & 14.7 \\
\hline \multicolumn{5}{|l|}{ Metastasis at diagnosis } \\
\hline No (metachronous, M0) & 489 & 58.1 & 184 & 55.1 \\
\hline Yes (synchronous, M1) & 248 & 29.5 & 97 & 29.0 \\
\hline $\mathrm{MX}^{\mathrm{b}} /$ Unknown & 105 & 12.5 & 53 & 15.9 \\
\hline \multicolumn{5}{|l|}{ Location of metastases ${ }^{\mathrm{d}, \mathrm{g}}$} \\
\hline Visceral \pm nonvisceral & 494 & 58.7 & 191 & 57.2 \\
\hline Nonvisceral only & 302 & 35.9 & 123 & 36.8 \\
\hline Unknown & 46 & 5.5 & 20 & 6.0 \\
\hline Bone only & 207 & 24.6 & 86 & 25.7 \\
\hline Liver only & 76 & 9.0 & 33 & 9.9 \\
\hline Lung only & 56 & 6.7 & 32 & 9.6 \\
\hline Brain & 27 & 3.2 & 3 & 0.9 \\
\hline Multiple and/or other location ${ }^{c}$ & 430 & 51.1 & 160 & 47.9 \\
\hline Unknown & 46 & 5.5 & 20 & 6.0 \\
\hline \multicolumn{5}{|l|}{ Number of metastatic sites ${ }^{\mathrm{d}}$} \\
\hline$=1$ & 445 & 52.9 & 179 & 53.6 \\
\hline$>1$ & 351 & 41.7 & 135 & 40.4 \\
\hline Unknown & 46 & 5.4 & 20 & 6.0 \\
\hline Preceding adjuvant therapy & 490 & 58.2 & 170 & 50.9 \\
\hline
\end{tabular}


Table 2 (continued)

$B M I$ body mass index $\left(\mathrm{kg} / \mathrm{m}^{2}\right), H R$ hormone receptor, HER2 human epidermal growth factor receptor 2, Max maximum, Min minimum

${ }^{a}$ Underweight: BMI < 18.5; normal: BMI 18.5 to $<25$, overweight: BMI 25 to $<30$, obese: BMI $\geq 30$

${ }^{\mathrm{b}} \mathrm{MX}$, presence of distant metastasis was not evaluated or is not documented for the time of primary diagnosis

${ }^{\mathrm{c}}$ Other locations than the aforementioned or multiple locations

${ }^{d}$ at start of palliative first-line therapy

${ }^{\mathrm{e}}$ At least one comorbidity according to Charlson [23] or additional concomitant diseases

${ }^{\mathrm{f}}$ Charlson Comorbidity Index (CCI) according to Quan et al. [24]

${ }^{\mathrm{g}}$ Nonvisceral: bone, lymph node and/or skin metastases

in elderly patients in palliative therapy ( $38 \% \mathrm{CCI} \geq 1 \mathrm{vs}$. $18 \%$ CCI $\geq 1$ ). The distribution of receptor subtypes was comparable in younger and older patients. Independent of age, a similar number of patients presented with synchronous metastasis (30 vs. $29 \%$ ), with nonvisceral (bone, skin and/or lymph node) metastases (36 vs. $37 \%$ ) or with more than one metastatic site (42 vs. $40 \%$ ). Referring to the location of the metastases, slightly more of the younger patients had brain metastases ( 3 vs. $1 \%$ ), whereas slightly more elderly patients had metastases in the lung ( 7 vs. $10 \%$ ). The proportion of patients with preceding adjuvant chemotherapy was a bit higher in the younger patient group (58\% vs. 51\%).

\section{Treatment}

Patients aged $\geq 70$ at start of therapy less often underwent a breast conserving surgery (BCS) than younger patients (58\%, 95\% CI $49-66 \%$ vs. $72 \%, 95 \%$ CI $69-75 \%$, Fig. 2a), and more often had a mastectomy $(42 \%, 95 \%$ CI $34-50 \%$ vs. $25 \%, 95 \%$ CI $22-27 \%$, Fig. 2b). After surgery, however, the same proportion of patients in both subgroups received radiotherapy, $81-85 \%$ after BCS and 55\% after mastectomy (Fig. 2a, b). The proportion of taxane-based chemotherapy was similar independent of the age in the adjuvant setting (61 vs. $62 \%$ ), while fewer elderly patients received this regimen in palliative first-line $(29 \%, 95 \%$ CI $23-37 \%$ vs. $36 \%$, 95\% CI 32-40\%, Fig. 2c). For patients with HER2-positive tumours, administration of anti-HER2-therapy in the adjuvant and palliative first-line setting was similar between the age groups (Fig. 2d). A higher proportion of elderly patients with HR-positive tumours received endocrine therapy only, $18 \%$ (95\% CI $11-27 \%$ ) versus $6 \%$ (95\% CI 5-8\%) in the adjuvant and 53\% (95\% CI 46-60\%) versus $41 \%$ (95\% CI $37-45 \%$ ) in the palliative setting (Fig. 2e).

\section{Treatment response and outcome data}

For all prospectively enrolled patients (see Fig. 1), response rates and outcome data according to the different treatment regimens are shown in Table 3. The median follow-up period was 41.3 months (range 33-53 months) for all patients, with only a slight difference between the age groups: 42.8 months (range 33-54 months) vs. 37.9 months (range $29-47$ months) for patients aged $\geq 70$.

In the adjuvant setting, duration of chemotherapy did not differ between younger and elderly patients. The DFS rates were comparable: $88 \%$ of the younger patients lived at least 36 months without recurrence compared to $86 \%$ of the patients aged $\geq 70$ (Table 3, Fig. 3a).

In the palliative first-line setting, duration of endocrine therapy in patients with HR-positive tumours was comparable (15.9 months, 95\% CI 13.3-20.2 vs. 15.4 months, 95\% CI 10.9-20.1). Endocrine therapy was successful in $55 \%$ younger and $46 \%$ elderly patients, as assessed by the disease control rate (DCR), covering complete/partial response and stable disease (CR/PR and SD; Table 3). Chemotherapy was successful in $68 \%$ of the younger and $60 \%$ of the elderly patients (DCR, Table 3 ). The median PFS was 12.2 months (95\% CI 10.8-13.3) for the younger and 7.6 months (95\% CI 6.6-8.9) for the elderly patients treated with chemotherapy. The OS analysis, calculated from start of first-line therapy, revealed that patients aged $\geq 70$ had a significantly shorter median OS of 24.9 months (95\% CI 20.0-30.2) compared to 39.7 months (95\% CI 34.9-44.2) for younger patients (Fig. 3b). Breast cancer was documented as cause of death for $85 \%$ of the younger patients and for $73 \%$ of the patients aged $\geq 70$. Median disease-specific survival was 46.3 months (95\% CI 40.2-54.2) for younger and 35.3 (95\% CI 25.5-40.5) months for elderly patients (Fig. 3c).

\section{Factors influencing overall survival}

A multivariate regression analysis showed that not only an age of $\geq 70$ at start of palliative first-line therapy, but also negative HR- and HER2-status, higher number of metastatic sites, higher $\mathrm{CCI}$ and high tumour grading at diagnosis were associated with a significantly increased risk of overall mortality (Fig. 4). In contrast, nonvisceral metastases (vs. visceral metastases), metastasis at diagnosis (synchronous (M1) vs. metachronous (M0)) as well as obesity (obese vs. normal) were associated with a decreased risk of mortality (Fig. 4). 

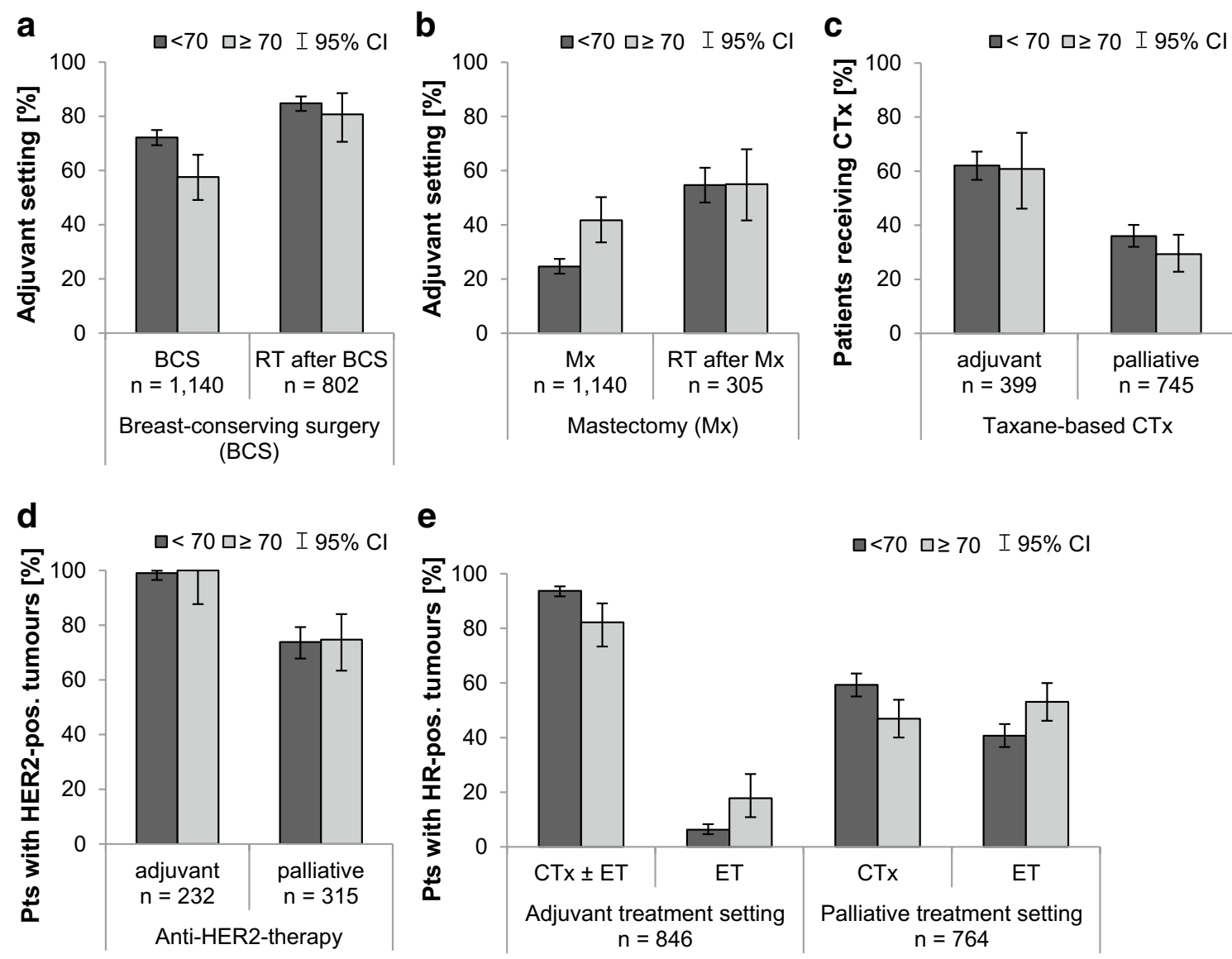

Fig. 2 Treatment of breast cancer for patients aged $<70$ in comparison to patients aged $\geq 70$. a Proportion of patients receiving breast conserving surgery (BCS) in the adjuvant treatment setting. The proportion of patients receiving radiotherapy (RT) is calculated for all patients receiving BCS. b Proportion of patients receiving mastectomy $(\mathrm{Mx})$ in the adjuvant treatment setting. The proportion of patients receiving radiotherapy is calculated for all patients receiving Mx. c Proportion of patients receiving taxane-based chemotherapy (of all patients receiving chemotherapy). d Proportion of patients receiving anti-HER2-therapy (of all patients with HER2-positive tumours). e Proportion of patients with HR-positive tumours receiv-

\section{Discussion}

The proportion of elderly patients with breast cancer is growing continuously. Treatment decisions should not be based on chronological age alone, but need to ensure that elderly patients get the best quality of care. We shed light on the medical management of patients aged $\geq 70$ in routine care, presenting data on treatment and outcome of 478 elderly and 1838 younger patients. In the adjuvant setting, elderly patients less often received chemotherapy. The 3-year DFS was similar to that of younger patients. In the palliative setting, the median OS of elderly patients was significantly shorter than that of younger patients, despite similar treatment. However, not only the age at start of therapy, but also the presence of comorbidities or metastases, negative HR- or ing systemic chemotherapy and/or endocrine therapy. In the adjuvant treatment setting, patients receiving chemotherapy and endocrine therapy as well as patients receiving only chemotherapy were added up. 114 younger patients (15.3\%) and 12 elderly patients (11.9\%) received chemotherapy without endocrine therapy. Error bars represent the 95\% confidence interval (CI) Abbreviations: BCS breast conserving surgery, $C I$ confidence interval, $C T x$ chemotherapy, ET endocrine therapy, HER2 human epidermal growth factor receptor 2, $H R$ hormone receptor, $M x$ mastectomy, pos positive, pts patients, $R T$ radiotherapy

HER2-status or high tumour grading at diagnosis significantly increased the risk of mortality.

This study is limited by the sole enrolment of patients receiving systemic therapy, potentially excluding patients refusing such treatment as well as very frail older patients not able to receive systemic therapy. The interpretation of data from cohort studies is limited by the lack of randomization which has to be considered when comparing outcome data between subgroups. In the TMK registry, there are no specifications as to the timing, frequency or criteria of tumour assessment and, thus DFS and PFS data should be considered as the best clinical approximation and might not be identical to the PFS determined in clinical trials. Strengths of this study are the prospective, longitudinal design and the participation of oncologists all over Germany. 
Table 3 Outcome data in the adjuvant and palliative setting

\begin{tabular}{|c|c|c|c|c|}
\hline Adjuvant setting (prospectively enrolled patients) & $<70(n=951)$ & & $\geq 70(n=139)$ & \\
\hline Patients receiving chemotherapy $(n, \%)$ & 714 & $75.1 \%$ & 92 & $66.2 \%$ \\
\hline Number of cycles (median, min-max) ${ }^{\mathrm{a}}$ & 6.0 & $3.0-6.0$ & 4.0 & $3.0-6.0$ \\
\hline Duration of CTx in months (median, $95 \%$ CI) ${ }^{\mathrm{b}}$ & 3.5 & NA-NA & 3.5 & $3.5-3.6$ \\
\hline End of CTx documented ${ }^{\mathrm{c}}(n, \%)$ & 709 & $99.3 \%$ & 91 & $98.9 \%$ \\
\hline Patients receiving targeted therapy $(n, \%)$ & 192 & $20.2 \%$ & 28 & $20.1 \%$ \\
\hline Number of cycles (median, range) ${ }^{\mathrm{d}}$ & 17.0 & $13.0-18.0$ & 18 & $12.0-18.0$ \\
\hline Duration of TT in months (median, 95\% CI) & 14.7 & $14.2-15.6$ & 15.2 & $11.7-16.6$ \\
\hline End of TT documented $(n, \%)$ & 189 & $98.4 \%$ & 27 & $96.4 \%$ \\
\hline Patients receiving endocrine therapy $(n, \%)$ & 615 & $64.7 \%$ & 90 & $64.7 \%$ \\
\hline Duration of ET in months (median, 95\% CI) & 59.5 & $58.5-61.9$ & 59.2 & 43.2-NA \\
\hline End of ET documented ${ }^{\mathrm{c}}(n, \%)$ & 159 & $25.9 \%$ & 25 & $27.8 \%$ \\
\hline Disease-free survival—all patients and treatments & 951 & $100 \%$ & 139 & $100 \%$ \\
\hline Events $(n, \%)$ & 110 & $11.6 \%$ & 19 & $13.7 \%$ \\
\hline Median DFS & NA & & NA & \\
\hline \multicolumn{5}{|l|}{ Survival rate $(\%, 95 \% \mathrm{CI})$} \\
\hline 12 months & $96.3 \%$ & $94.8-97.3$ & $94.0 \%$ & $88.3-97.0$ \\
\hline 24 months & $91.4 \%$ & $89.2-93.1$ & $90.2 \%$ & $83.4-94.4$ \\
\hline 36 months & $87.8 \%$ & $85.3-89.9$ & $85.5 \%$ & $77.1-91.0$ \\
\hline Palliative first-line setting (prospectively enrolled patients) & $<70(n=554)$ & & $\geq 70(n=239)$ & \\
\hline Patients receiving endocrine therapy $(n, \%)$ & 132 & $23.8 \%$ & 85 & $35.6 \%$ \\
\hline Duration of ET in months (median, 95\% CI) & 15.9 & $13.3-20.2$ & 15.4 & $10.9-20.1$ \\
\hline \multicolumn{5}{|l|}{ Best response } \\
\hline $\mathrm{CR} / \mathrm{PR}$ & 26 & $19.7 \%$ & 12 & $14.1 \%$ \\
\hline SD & 46 & $34.8 \%$ & 27 & $31.8 \%$ \\
\hline PD & 24 & $18.2 \%$ & 19 & $22.4 \%$ \\
\hline Missing & 36 & $27.3 \%$ & 27 & $31.8 \%$ \\
\hline Patients receiving chemotherapy $(n, \%)$ & 422 & $76.2 \%$ & 154 & $64.4 \%$ \\
\hline Duration of $\mathrm{CTx}^{\mathrm{a}}$ in months (median, $95 \% \mathrm{CI}$ ) & 5.1 & $4.6-5.8$ & 3.8 & $3.5-4.9$ \\
\hline \multicolumn{5}{|l|}{ Best response } \\
\hline $\mathrm{CR} / \mathrm{PR}$ & 173 & $41.0 \%$ & 52 & $33.8 \%$ \\
\hline $\mathrm{SD}$ & 115 & $27.3 \%$ & 41 & $26.6 \%$ \\
\hline PD & 66 & $15.6 \%$ & 34 & $22.1 \%$ \\
\hline Missing & 68 & $16.1 \%$ & 27 & $17.5 \%$ \\
\hline Progression-free survival & 420 & $75.8 \%$ & 152 & $63.6 \%$ \\
\hline Events $(n, \%)$ & 237 & $56.2 \%$ & 102 & $66.2 \%$ \\
\hline Median PFS (months, 95\% CI) & 12.2 & $10.8-13.3$ & 7.6 & $6.6-8.9$ \\
\hline Overall survival—all patients and treatments & 554 & $100 \%$ & 239 & $100 \%$ \\
\hline Events $(n, \%)$ & 275 & $49.6 \%$ & 146 & $61.1 \%$ \\
\hline Median OS (months, 95\% CI) & 39.7 & $34.9-44.2$ & 24.9 & $19.9-30.1$ \\
\hline \multicolumn{5}{|l|}{ Survival rate $(\%, 95 \% \mathrm{CI})$} \\
\hline 12 months & $83.8 \%$ & $80.4-86.7$ & $71.6 \%$ & $65.3-77.0$ \\
\hline 24 months & $68.2 \%$ & $63.9-72.1$ & $51.6 \%$ & $44.7-58.0$ \\
\hline 36 months & $53.5 \%$ & $48.8-57.9$ & $37.8 \%$ & $31.0-44.5$ \\
\hline
\end{tabular}

Duration of therapy was calculated with a Kaplan-Meier estimate

$C I$ confidence interval, $C R$ complete response, $C T x$ chemotherapy, $E T$ endocrine therapy; NA, not available (not reached); OS, overall survival, $P D$ progressive disease, $P F S$ progression-free survival, $P R$ partial response, $S D$ stable disease, $S t D$ standard deviation, $T T$ targeted therapy

${ }^{a}$ For all patients with available data on this parameter: $<70, n=708 ; \geq 70, n=91$

${ }^{\mathrm{b}}$ Without targeted therapy (TT)

${ }^{c}$ Patients who completed the respective treatment within the follow-up period of this cohort study. Percentages refer to all patients receiving the respective treatment

${ }^{\mathrm{d}}$ For all patients with available data on this parameter: $<70, n=179 ; \geq 70, n=25$ 
Fig. 3 Survival of patients aged $<70$ compared to patients aged $\geq 70$. Survival analysis for the prospectively enrolled patients (see Fig. 1). a DFS for the patients with (neo) adjuvant treatment intention, b OS for the patients with palliative treatment intention, $\mathbf{c}$ Disease-specific survival for the patients in the palliative setting. Abbreviations: $\mathrm{CCI}$ Charlson Comorbidity Index, $C I$ confidence interval, $D F S$ disease-free survival; $D S S$ disease-specific survival, $O S$ overall survival a Disease-free survival

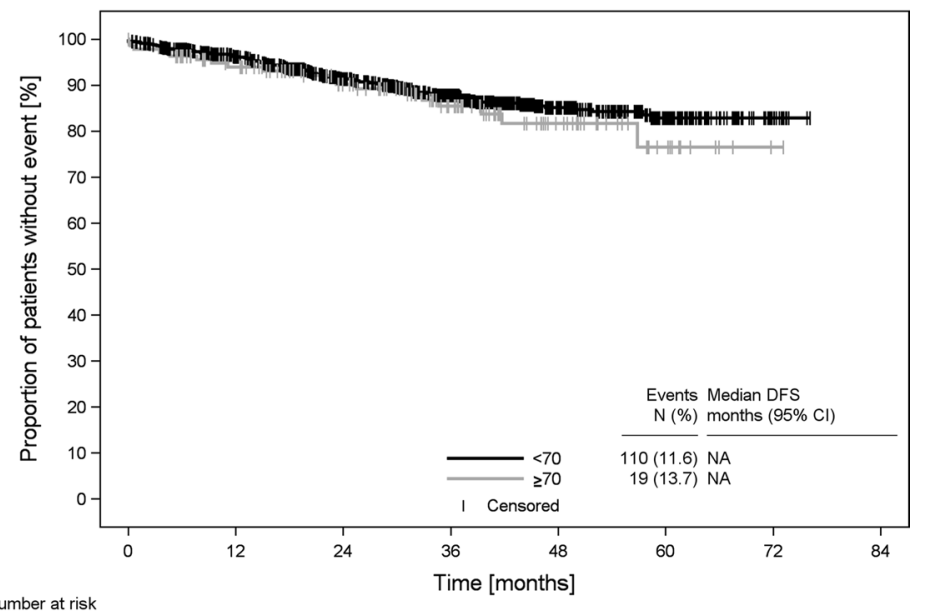

Number at risk

$\begin{array}{lllllllll}<70 & 951 & 807 & 645 & 453 & 230 & 92 & 13 & 0 \\ \geq 70 & 139 & 116 & 90 & 61 & 30 & 11 & 1 & 0\end{array}$

b Overall survival

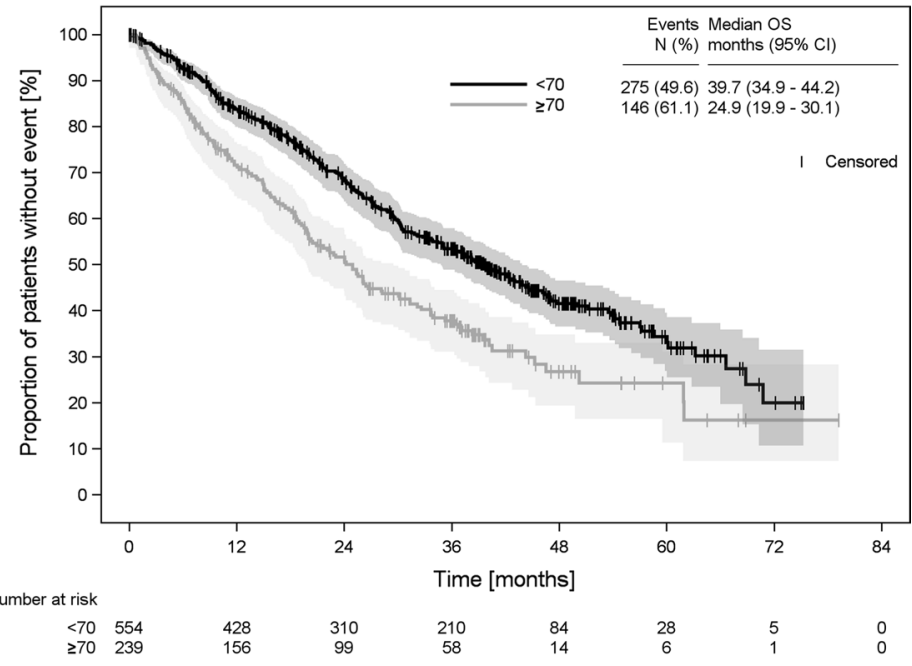

c Disease-specific survival

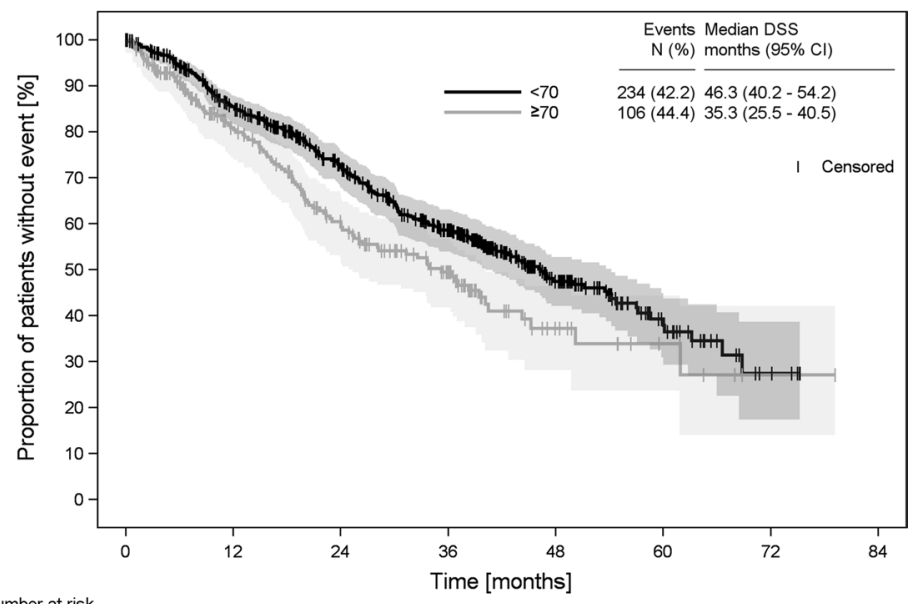

Number at risk

$\begin{array}{llllccccc}<70 & 554 & 428 & 310 & 210 & 84 & 28 & 5 & 0 \\ \geq 70 & 239 & 156 & 99 & 58 & 14 & 6 & 1 & 0\end{array}$ 
Fig. 4 Multivariate regression analysis. Cox proportional hazards model for overall survival. Bold writing: significant results $(p<0.05)$. *Metastasis at diagnosis was documented either synchronous (M1) or metachronous (M0). Abbreviations: $B M I$ body mass index, CCI Charlson Comorbidity Index, $C I$ confidence interval, $H R$ hazard ratio, HER2 human epidermal growth factor receptor 2, metachr metachronous, synchr synchronous

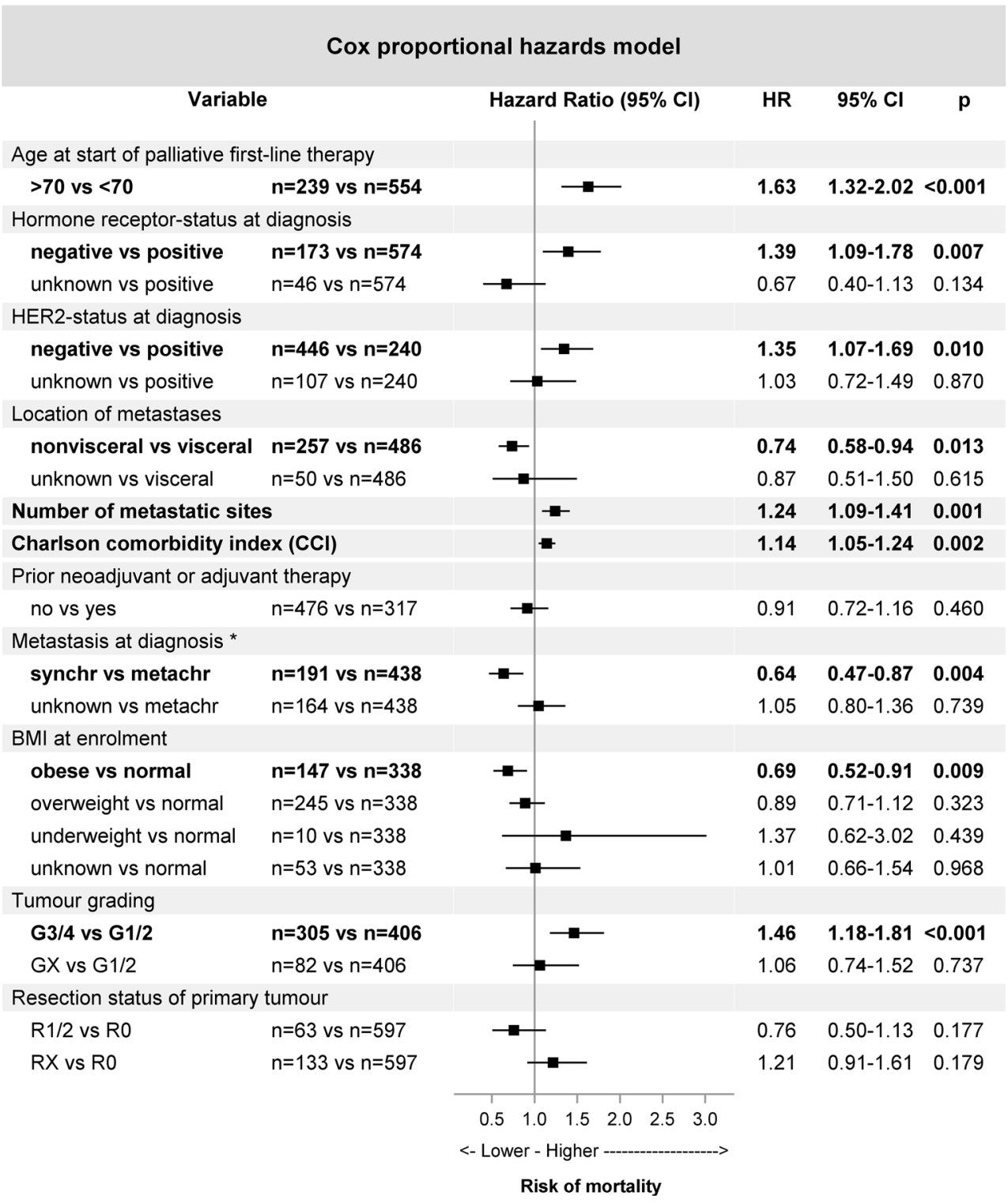

At what chronological age is a patient defined as 'elderly'? Even this simple question raises multiple issues and complicates comparisons between studies. Some authors set the threshold at $\geq 65$ years [13], others at $\geq 70[10,11$, 25 ] or even at $\geq 80$ years [26]. The NCCN task force report on breast cancer in the older woman recommended the cutoff point '70 years or older', as there is almost no clinical evidence for treatment of this patient subgroup [14], rendering prospective cohort studies like ours important information resources on the patients aged $\geq 70$.

Poor diagnostic assessment, one of the factors for substandard treatment, was not observed in the SENORA cohort. The proportion of adjuvant patients with unknown/ undocumented receptor status, tumour or nodal stage was similar in both age groups. It has been shown that patients aged $\geq 55$ often have a more advanced disease at diagnosis, yet slower proliferation rates and less aggressive tumour profiles, including a higher proportion of HR-positive tumours [8]. Consistent with these reports, $26 \%$ of the elderly patients in the SENORA cohort were initially diagnosed with tumour stage III compared to $14 \%$ of the younger patients. The finding that patients aged $>70$ more frequently present with more advanced tumours might be a consequence of recommendations for screening mammograms, which have only been established for the age groups between 50 and 70 years [27]. The HR-positive tumours, however, were equally distributed over the age groups. Although no differences in tolerance of BCS or mastectomy have been shown due to age [28], elderly patients are more often treated with mastectomy [13]. Indeed, our results show that $42 \%$ of the elderly patients underwent mastectomy, compared to $24 \%$ of the younger women. This tendency is in concordance with 
the NORA cohort study showing that $49 \%$ of the patients aged $\geq 70$ versus $40 \%$ of the patients aged $65-69$ were treated with mastectomy [13]. The value of adjuvant chemotherapy in the elderly population is controversial (reviewed in 30) and it has been reported that few elderly patients who are candidates for chemotherapy actually receive it $[19,29]$. Of the prospectively enrolled patients with adjuvant treatment intention, $75 \%$ of the younger and $66 \%$ of the elderly patients received adjuvant chemotherapy, although the proportion of patients with more advanced tumour stages was higher in the elderly group. Interestingly, the 3-year DFS rate was similar between both groups and comparable to previously published data [30]. The number of cycles and duration of treatment was similar between the age groups. In short, 'substandard treatment' of elderly patients was not observed in our setting.

For the patients aged $\geq 70$ with palliative treatment intention, median OS was significantly shorter than that of the younger patients (24.9 compared to 39.7 months). This difference was markedly reduced in the DSS, implicating that not only the breast cancer, but also other factors influence the survival of elderly patients. Indeed, a Cox proportional hazards model showed that not only higher age at diagnosis, but also comorbidities, a higher number of metastatic sites, high tumour grading or negative HR- or HER2-status increased the risk of mortality. These results are in concordance with the literature about prognostic factors in metastatic breast cancer [7, 31-33]. Interestingly, obesity (BMI $\geq 30)$ was associated with a decreased risk of mortality, the opposite of what was shown previously [34]. Synchronous metastasis at diagnosis was also favourable, a fact that could be attributed to the missing previous adjuvant chemotherapy, which has been identified as predicting factor negatively influencing survival [7, $35,36]$. Thus, the assessment of treatment and outcome of elderly patients should consider that factors other than age also affect decision making and prognosis.

\section{Conclusions}

The results from the SENORA project add valuable information to the ongoing debate about 'undertreatment' of elderly patients-there was no substantial difference in the treatment of elderly women with breast cancer in German routine care. Age was but one of various prognostic factors influencing the survival of elderly patients anddespite similar treatment-the overall survival of patients aged $\geq 70$ was shorter.

Acknowledgements The authors thank all patients, physicians and study teams participating in the TMK. We thank Dr. Iris Benz-Rüd
(iOMEDICO) for the support and comments during design and setup of the project, Michaela Schnitzler and Natalie Wetzel (iOMEDICO) for the support with the statistical analysis, Dr. Leonora Houet (iOMEDICO) for critical comments on the manuscript and Dr. Stephanie Dille (iOMEDICO) for preparation of the manuscript. The TMK is designed, managed and analysed by iOMEDICO and has received continuous financial support from Roche Pharma AG and temporary financial support from AstraZeneca GmbH, NeoCorp AG, Novartis Pharma GmbH, Onkovis $\mathrm{GmbH}$ and Pfizer GmbH. This publication was financially supported by Hexal AG. None of the funders had any role in study design, data collection and analysis, interpretation of results, decision to publish or preparation of the manuscript. The TMK Study Group collaborates with the Arbeitskreis Klinische Studien in onkologischen und hämatologischen Praxen e.V. and the Arbeitsgemeinschaft Internistische Onkologie in der deutschen Krebsgesellschaft e.V.

\section{Compliance with ethical standards}

Conflict of interest TF declares a consultant/advisory role for Teva, Novartis, Sanofi-Aventis, Roche and Boehringer Ingelheim. AK has received travel expenses from Roche, Novartis, Celgene and Amgen for attendance of advisory boards. NM has received travel expenses from Roche, Novartis, Celgene and Amgen for attendance of advisory boards and scientific meetings. All other authors declare no conflict of interest concerning the topic of this publication.

Research involving human and animal rights All procedures performed in studies involving human participants were in accordance with the ethical standards of the institutional and/or national research committee and with the 1964 Helsinki declaration and its later amendments or comparable ethical standards.

Informed consent Informed consent was obtained from all individual participants included in the study.

Open Access This article is distributed under the terms of the Creative Commons Attribution 4.0 International License (http://creativecommons.org/licenses/by/4.0/), which permits unrestricted use, distribution, and reproduction in any medium, provided you give appropriate credit to the original author(s) and the source, provide a link to the Creative Commons license, and indicate if changes were made.

\section{References}

1. Robert Koch Institut (2015) Krebs in Deutschland 2011/2012, 10. Ausgabe. Robert Koch-Institut, Berlin

2. Zentrum für Krebsregisterdaten im Robert Koch-Institut Krebs Datenbankabfrage. http://www.krebsdaten.de/abfrage. Accessed 5 Apr 2016

3. Statistisches Bundesamt Lange Reihen: Bevölkerung nach Altersgruppen, 13. koordinierte Bevölkerungsvorausberechnung: Bevölkerung Deutschlands bis 2060

4. Statistisches Bundesamt (2016) Sterbetafel 2012/2014 Deutschland weiblich. Wiesbaden

5. Ali AMG, Greenberg D, Wishart GC, Pharoah P (2011) Patient and tumour characteristics, management, and age-specific survival in women with breast cancer in the East of England. Br J Cancer 104:564-570

6. Janssen-Heijnen ML, Houterman S, Lemmens VE et al (2005) Prognostic impact of increasing age and co-morbidity in cancer 
patients: a population-based approach. Crit Rev Oncol Hematol 55:231-240

7. Largillier R, Ferrero J-M, Doyen J et al (2008) Prognostic factors in 1,038 women with metastatic breast cancer. Ann Oncol Off J Eur Soc Med Oncol ESMO 19:2012-2019. doi:10.1093/ annonc/mdn 424

8. Diab SG, Elledge RM, Clark GM (2000) Tumor characteristics and clinical outcome of elderly women with breast cancer. $\mathrm{J}$ Natl Cancer Inst 92:550-556

9. Daidone MG, Coradini D, Martelli G, Veneroni S (2003) Primary breast cancer in elderly women: biological profile and relation with clinical outcome. Crit Rev Oncol Hematol 45:313-325

10. Eaker S, Dickman PW, Bergkvist L et al (2006) Differences in management of older women influence breast cancer survival: results from a population-based database in Sweden. PLoS Med. doi:10.1371/journal.pmed.0030025

11. Rosso S, Gondos A, Zanetti R et al (2010) Up-to-date estimates of breast cancer survival for the years 2000-2004 in 11 European countries: the role of screening and a comparison with data from the United States. Eur J Cancer Oxf Engl 1990 46:3351-3357. doi:10.1016/j.ejca.2010.09.019

12. O'Connor T, Shinde A, Doan C et al (2013) Managing breast cancer in the older patient. Clin Adv Hematol Oncol HO 11:341-347

13. Mustacchi G, Cazzaniga ME, Pronzato P et al (2007) Breast cancer in elderly women: a different reality? Results from the NORA study. Ann Oncol 18:991-996

14. Carlson RW, Moench S, Hurria A et al (2008) NCCN task force report: breast cancer in the older woman. J Natl Compr Cancer Netw JNCCN 6(Suppl 4):S1-s25 quiz S26-27

15. Smith BD, Jiang J, McLaughlin SS et al (2011) Improvement in breast cancer outcomes over time: are older women missing out? J Clin Oncol 29:4647-4653

16. Bouchardy C, Rapiti E, Blagojevic S et al (2007) Older female cancer patients: importance, causes, and consequences of undertreatment. J Clin Oncol Off J Am Soc Clin Oncol 25:1858-1869. doi:10.1200/JCO.2006.10.4208

17. Ring A, Reed M, Leonard R et al (2011) The treatment of early breast cancer in women over the age of 70 . Br J Cancer 105:189-193

18. Crivellari D, Aapro M, Leonard R et al (2007) Breast cancer in the elderly. J Clin Oncol Off J Am Soc Clin Oncol 25:1882-1890. doi:10.1200/JCO.2006.10.2079

19. Giordano SH, Hortobagyi GN, Kau S-WC et al (2005) Breast cancer treatment guidelines in older women. J Clin Oncol Off J Am Soc Clin Oncol 23:783-791. doi:10.1200/JCO.2005.04.175

20. Wildiers H, Heeren P, Puts M et al (2014) International society of geriatric oncology consensus on geriatric assessment in older patients with cancer. J Clin Oncol Off J Am Soc Clin Oncol 32:2595-2603. doi:10.1200/JCO.2013.54.8347

21. Fietz T, Tesch H, Rauh J, et al (in revision) Palliative systemic therapy and overall survival of 1,395 patients with advanced breast cancer-results from the prospective German TMK cohort study

22. Schemper M, Smith TL (1996) A note on quantifying follow-up in studies of failure time. Control Clin Trials 17:343-346
23. Charlson ME, Pompei P, Ales KL, MacKenzie CR (1987) A new method of classifying prognostic comorbidity in longitudinal studies: development and validation. J Chronic Dis 40:373-383

24. Quan H, Li B, Couris CM et al (2011) Updating and validating the Charlson comorbidity index and score for risk adjustment in hospital discharge abstracts using data from 6 countries. Am J Epidemiol 173:676-682. doi:10.1093/aje/kwq433

25. İnal $A, A k m a n T$, Yaman $S$ et al (2014) Pathologic and clinical characteristics of elderly patients with breast cancer: a retrospective analysis of a multicenter study (anatolian society of medical oncology). Int Surg 99:2-7. doi:10.9738/INTSURG-D-13-00010

26. Bouchardy C, Rapiti E, Fioretta G et al (2003) Undertreatment strongly decreases prognosis of breast cancer in elderly women. $\mathrm{J}$ Clin Oncol Off J Am Soc Clin Oncol 21:3580-3587. doi:10.1200/ JCO.2003.02.046

27. Liedtke C, Thill M, Committee on behalf of the AB (2016) AGO recommendations for the diagnosis and treatment of patients with early breast cancer: update 2016. Breast Care 11:204-214. doi:10.1159/000446941

28. Audisio RA, Bozzetti F, Gennari R et al (2004) The surgical management of elderly cancer patients. Eur J Cancer 40:926-938. doi:10.1016/j.ejca.2004.01.016

29. DeMichele A, Putt M, Zhang Y et al (2003) Older age predicts a decline in adjuvant chemotherapy recommendations for patients with breast carcinoma: evidence from a tertiary care cohort of chemotherapy-eligible patients. Cancer 97:2150-2159. doi: $10.1002 /$ cncr. 11338

30. Dall P, Lenzen G, Göhler T et al (2015) Trastuzumab in the treatment of elderly patients with early breast cancer: results from an observational study in Germany. J Geriatr Oncol 6:462-469. doi:10.1016/j.jgo.2015.06.003

31. Kwast ABG, Voogd AC, Menke-Pluijmers MBE et al (2014) Prognostic factors for survival in metastatic breast cancer by hormone receptor status. Breast Cancer Res Treat 145:503-511. doi:10.1007/s10549-014-2964-0

32. Regierer AC, Wolters R, Ufen M-P et al (2014) An internally and externally validated prognostic score for metastatic breast cancer: analysis of 2269 patients. Ann Oncol Off J Eur Soc Med Oncol ESMO 25:633-638. doi:10.1093/annonc/mdt539

33. Yardley DA, Tripathy D, Brufsky AM et al (2014) Long-term survivor characteristics in HER2-positive metastatic breast cancer from registHER. Br J Cancer 110:2756-2764. doi:10.1038/ bjc. 2014.174

34. Hauner D, Janni W, Rack B, Hauner H (2011) The effect of overweight and nutrition on prognosis in breast cancer. Dtsch Arzteblatt Int 108:795-801. doi:10.3238/arztebl.2011.0795

35. Alba E, Ribelles N, Sevilla I et al (2001) Adjuvant anthracycline therapy as a prognostic factor in metastatic breast cancer. Breast Cancer Res Treat 66:33-39

36. Insa A, Lluch A, Prosper F et al (1999) Prognostic factors predicting survival from first recurrence in patients with metastatic breast cancer: analysis of 439 patients. Breast Cancer Res Treat $56: 67-78$ 